\title{
A comprehensive simulation approach for pollutant bio-transformation in the gravity sewer
}

\author{
Nan Zhao', Huu Hao Ngo ${ }^{2}$, Yuyou $\mathrm{Li}^{3}$, Xiaochang Wang ${ }^{1}$, Lei Yang ${ }^{1}$, Pengkang Jin (凶) ${ }^{1}$, Guangxi Sun ${ }^{4}$ \\ 1 School of Environmental and Municipal Engineering, Xi'an University of Architecture and Technology, Xi'an 710055, China \\ 2 Centre for Technology in Water and Wastewater, School of Civil and Environmental Engineering, \\ University of Technology, Sydney, NSW 2007, Australia \\ 3 Department of Civil and Environmental Engineering, Tohoku University, Sendai, Miyagi 980-8579, Japan \\ 4 Research Center for Eco-Environmental Sciences, Chinese Academy of Sciences, Beijing 100085, China
}

\section{H I G H L I G H T S}

- A comprehensive pollutant transformation model for sewer systems is established.

- The model comprises fermentation, sulfate reduction and ammonification processes.

- Biochemical reactions related to distinct carbon sources are depicted in the model.

- Pollutant transformation is attributed to different biochemical reaction processes.

Keywords:

Gravity sewer

Modeling

Pollutant transformation

Biochemical reaction process

\section{A B S T R A C T}

Presently, several activated sludge models (ASMs) have been developed to describe a few biochemical processes. However, the commonly used ASM neither clearly describe the migratory transformation characteristics of fermentation nor depict the relationship between the carbon source and biochemical reactions. In addition, these models also do not describe both ammonification and the integrated metabolic processes in sewage transportation. In view of these limitations, we developed a new and comprehensive model that introduces anaerobic fermentation into the ASM and simulates the process of sulfate reduction, ammonification, hydrolysis, acidogenesis and methanogenesis in a gravity sewer. The model correctly predicts the transformation of organics including proteins, lipids, polysaccharides, etc. The simulation results show that the degradation of organics easily generates acetic acid in the sewer system and the high yield of acetic acid is closely linked to methanogenic metabolism. Moreover, propionic acid is the crucial substrate for sulfate reduction and ammonification tends to be affected by the concentration of amino acids. Our model provides a promnising tool for simulating and predicting outcomes in response to variations in wastewater quality in sewers.

C Corresponding author

E-mail: pkjin@hotmail.com

\section{Introduction}

The sewer system is an important component of urban water infrastructure. It collects and transports wastewater from residences houses to wastewater treatment plants. Relevant studies (Schmitt and Seyfried, 1992; Jiang et al., 2009; Ren et al., 2017) have shown that biofilms can form 
on the inner wall of pipes during sewage transport and degrade the macromolecules into smaller molecules, leading to variations in the water quality within the sewer. Jin et al. (2018) reported that these variations not only caused significant differences between the expected values of water quality and the actual influent quality in wastewater treatment plants but also influenced the efficiency of the treatment system.

To predict the actual influent quality of wastewater treatment plants, the bio-transformation of pollutants in sewers needs to be modeling. Ever since "the sewer as reactors" concept was first proposed in Denmark in 1994, many sewer models have been developed (Schmitt and Seyfried, 1992; Garsdal et al., 1995; Jiang et al., 2009). The first model was developed by Garsdal et al. (1995) and emphasized the changes in the biochemical oxygen demand of sewers. The activated sludge model (ASM) was later developed to simulate the quality of water in sewers and soon became popular. Using beaker experiments and other methods in sewer investigations, HvitvedJacobsen et al. (1998) analyzed the actual applicability of the ASM and measured the relevant parameters of the ASM in sewers. The ASM was further optimized based on variations in sewage flow, resulting in the Wastewater Aerobic-anaerobic Transformations in Sewers (WATS) model, which can be applied to simultaneously predict gravity flow and pressure flow drainage under aerobic, anoxic and anaerobic conditions (Abdul-Talib et al., 2002; Rudelle et al., 2011). Furthermore, to investigate the metabolism of sewage contaminants by biofilm, Huisman and Gujer (2002) developed a joint model simulating a $2-\mathrm{km}$ long sewer by combining the ASM-3 and the biofilm multiple substrate model (BMSM) to examine changes in water quality and microorganisms. Advances in computer science have allowed more algorithms to be applied to the ASM. Jiang et al. (2007) applied a genetic algorithm to produce an accurate adaptation of ASM-3 for sewers. In another advancement, Fu et al. (2010) applied a neural network algorithm on an appreciable quantity of rainfall data and the ASM to simulate the migration and transformation of pollutants.

Although these models have been widely applied to simulate sewer systems, it has been difficult to include processes such as fermentation and sulfate reduction which are important for the transformation of pollutants in sewer systems. Hence, three popular models were created or improved to meet these demands. Jiang et al. (2009) improved the ASM model to enable the simulation of sulfate transformation. Meanwhile, based on the WATS model and the sulfur changes studied by HvitvedJacobsen, Rudelle et al. (2011) proposed an anaerobic digestion model that could simulate the regularity of sulfur changes for the different valences of sulfur. In addition, the SeweX model, which was first developed to simply simulate both the transformation of substances during fermentation and the sulfate changes based on the BMSM, WATS and the first-order model, was improved by Guisasola et al. (2009) by considering the fermentation process. Specifically, the fermentation process was divided into three main steps: First, glucose is metabolized into propionic acid (HPro); second, HPro is metabolized into acetic acid (HAc); and finally, HAc is used by methanogens to generate methane. Because sewer $\mathrm{pH}$ may fluctuate, and such fluctuations influence the generation of $\mathrm{H}_{2} \mathrm{~S}$; Sharma and colleagues further extended SeweX by adding a $\mathrm{pH}$ model and $\mathrm{pH}$ inhibitory factors (Sharma et al., 2013; Sharma et al., 2014).

Despite improving upon the ASM, these models only represent a few aspects of wastewater transformation fates or microbial growth, and sewer processes remain difficult to predict comprehensively. Specifically, the following limitations still remain:

First, although many models describe the fermentation process, few of them can clearly describe the sources of fermentation substrates or the migratory transformation characteristics of fermentation.

Second, the methane production process of previous models only consider acetic acid or fermented substances as the sole substrate for methanogenesis. These models ignore the conversion of $\mathrm{H}_{2}, \mathrm{CO}_{2}$ and methyl organic matters to methane.

Third, in the nitrogen transformation processes, ammonification and urea degradation have been demonstrated to be two of the most important processes occurring in sewers (Pandey et al., 2016; Mackey et al., 2016). However, previous studies have not provided a clear description of these two steps, i.e., no model describes the source and fates of nitrogenous compounds, such as proteins, amino acids and urea in sewers.

Fourth, although the aforementioned models, namely, WATS and SeweX, assume that volatile fatty acids (VFAs) are metabolized in the sulfate reduction process, these models do not clearly depict the effect of different VFA substrates on sulfate reduction.

Taking these limitations into consideration, we built a comprehensive sewer model named the Sewer Wastewater Transformation Model (SWTM). The model takes the advantages of the merits of the ASM and further introduces the process of anaerobic fermentation, methanogenesis, ammonification and sulfate reduction. To validate the improved model, its parameter values were determined using the data collected from a 1200-m sewer reactor fed with synthetic wastewater according to our previous study results (Jin et al., 2015). Finally, the model was further verified by comparing its outcomes to relevant literature data. On the basis of these proofs, we present a model that provides not only a promising comprehensive approach to simulate the variations in wastewater quality by elucidating contaminant transformations in sewers, but also a theoretical foundation for designing and operating wastewater treatment plants. 


\section{Model development}

\subsection{Schematic structure of the SWTM model}

Based on how organic substrates are utilized in sewage systems, we included three significant processes in the SWTM (Fig. 1): fermentation, ammonification and sulfate reduction, which are assumed to occur simultaneously. Due to the low concentrations of nitrate and nitrite in sewers (Jin et al., 2015), the denitrification can be ignored. Hence, the SWTM comprises six sub-models: hydrolysis, acidogenesis, acetogenesis, methanogenesis, sulfate reduction and ammonification. These are explained in detail below.

\subsubsection{Hydrolysis}

The hydrolysis sub-model has been expanded to incorporate two steps, as indicated by the results of a previous study (Jin et al., 2015). First, refractory pollutants are metabolized into slowly degradable organic matter such as lipids, proteins and polysaccharides. Second, lipids, proteins and polysaccharides are further metabolized into fatty acids, amino acids and sugars. These two processes occur at the same time.

\subsubsection{Acidogenesis}

Acidogenesis is divided into the following stages: first, rapidly degradable organics (glucose, amino acids, fatty acids, etc.) are metabolized into substrates such as butyric acid $(\mathrm{HBu})$, HPro, lactic acid, HAc and ethanol. In the second stage, the substrates ethanol, lactic acid, $\mathrm{H}_{2}$, HPro, and other VFAs are transformed into HAc (Vavilin, 2002; Jin et al., 2015).

\subsubsection{Methanogenesis}

The methanogenic process is carried out through three reactions that involve three different carbon sources: HAc, $\mathrm{CO}_{2}$, and methyl substrates (formic acid, methanol, methylamine) (Rahman et al., 2011).

\subsubsection{Homoacetogenesis}

In this process, carbon dioxide and an electron donor $\left(\mathrm{H}_{2}\right)$ are transformed into acetic acid in a process that is accomplished by homoacetogenic bacteria (Nie et al., 2007).

\subsubsection{Sulfate reduction}

Many substrates involved in this reaction include VFAs (Higashioka et al., 2009; Jie et al., 2014), long-chain fatty acids and soluble macromolecular organic compounds (Widdel and Pfennig, 1977; Cravo-Laureau et al., 2007). However, Jing et al. (2013) demonstrated that sulfatereducing bacteria (SRB) prefer small organic molecules as electron donors. Moreover, a recent study shows that the concentrations of ethanol, formic acid, valeric acid and hexanoic acid are very low in sewers (Jie et al., 2014). Therefore, we assume that the electron donors for sulfate reduction are mainly $\mathrm{HBu}$, HPro and HAc.

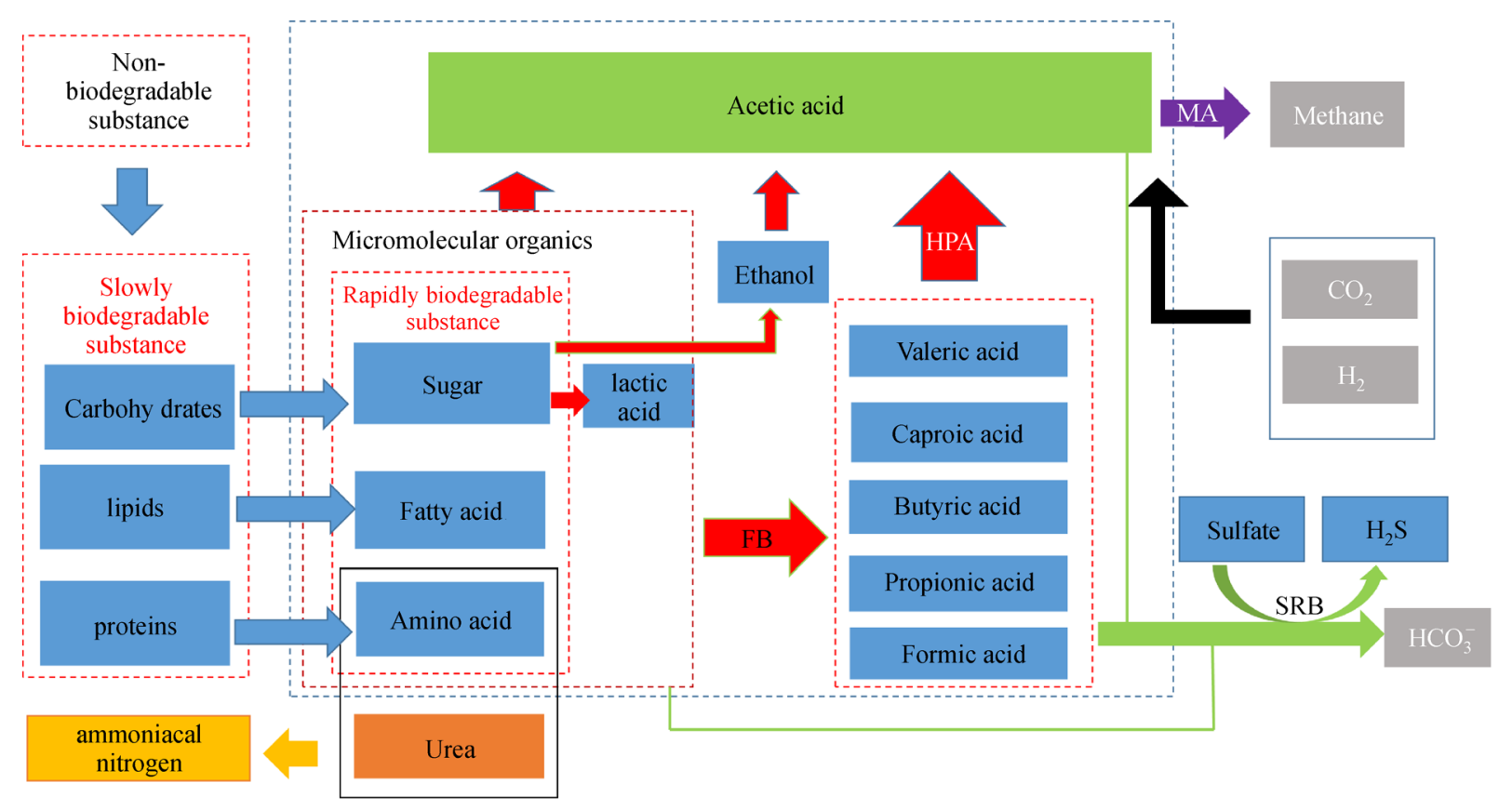

Fig. 1 Schematic structure of the SWTM: hydrolysis (blue arrows); acidogenesis (red arrows); homoacetogenesis (black arrows); methanogenesis (purple arrows); sulfate reduction (green arrows) and ammonification (orange lines). 


\subsubsection{Ammonification}

Two types of reactions are involved in this nitrogen conversion process. The first is urea hydrolysis, and the second is protein degradation, during which proteins are first transformed into amino acids, and then further biodegraded into ammonia. Because the hydrolysis of proteins is included in Sect. 2.1.1, ammonification mainly focuses on the transformation of amino acids and urea into ammonia.

\subsection{Introduction of the ADM-1 model to the SWTM}

The majority of the processes mentioned above are included in the IWA anaerobic digestion model No. 1 (ADM-1). Therefore, the SWTM was developed by adapting ADM-1. However, because ADM-1 does not include the conversion of sugar into lactic acid and ethanol, urea ammonification, sulfate reduction and other processes that play crucial roles in sewers, the SWTM was modified to meet these demands. The modifications are listed below, and all parameters are listed in the nomenclature:

1) Uptake of sugar

The process of "uptake of sugar" in the ADM model was modified. This modification was based on the chemical equations for sugar to lactic acid and ethanol by fermentative bacteria (FB) (Yuan et al., 2011; Sharma et al., 2013). The coefficient values of the process and the generation rates of lactic acid and ethanol were added to the model. These rate values are 26 ( $\mathrm{kg}$ COD-substrate $/(\mathrm{kg}$ COD-biomass $\cdot \mathrm{d})),\left(1-Y_{\text {su }}\right) * f_{\text {lactic }}$ and $\left(1-Y_{\text {su }}\right) * f_{\text {alcohol }}$, respectively.

2) Uptake of lactic acid

The process of "uptake of lactic acid" was introduced in the model. Vavilin (2002) showed that this process is similar to that of sugar. However, lactic acid is converted into HPro, $\mathrm{HAc}, \mathrm{H}_{2}$ and $\mathrm{CO}_{2}$. To describe these processes, the model adapts the Monod equation to provide proportional values to these processes according to the variations of the substrates participating in these processes. The Monod equation is given in Eq. (1) and the proportional values are listed in Table S.1.

$$
\mathrm{d} S / \mathrm{d} t=K_{\text {m,lactic }} * S_{\text {lactic }} /\left(S_{\text {lactic }}+K_{\text {lactic }}\right) .
$$

3) Uptake of ethanol

The process of "uptake of ethanol" was added to the SWTM model. This process is accomplished mainly by hydrogen-producing acetogens (HPA) (Ren et al., 1997). Therefore, the Monod equation is used to simulate the uptake of ethanol as shown in Eq. (2). Based on the chemical equation of ethanol conversion to HAc, the rates of generation of $\mathrm{H}_{2}$ and $\mathrm{HAc}$ from ethanol are $0.2 *$ $\left(1-Y_{\text {alcohol }}\right)$ and $0.8 *\left(1-Y_{\text {alcohol }}\right)$, respectively.

$$
\mathrm{d} S / \mathrm{d} t=K_{\text {m,alcohol }} * S_{\text {alcohol }} /\left(S_{\text {alcohol }}+K_{\text {alcohol }}\right) * X_{\text {alcohol }} \text {. }
$$

4) Homoacetogenic process

The homoacetogenic process of the ADM model was modified. The Monod equation was also employed in the homoacetogenic process in a similar manner as the above processes. In the equation, the rates of generation of $\mathrm{H}_{2}$ and HAc are -1 and $\left(1-Y_{\text {homo }}\right)$, respectively. The Monod equation is shown as Eq. (3).

$$
\mathrm{d} S / \mathrm{d} t=S_{m, \text { homo }} * S_{\mathrm{H}_{2}} /\left(S_{\mathrm{H}_{2}}+K_{s, \text { homo }}\right) * X_{\text {homo }} .
$$

5) Methanogenesis with $\mathrm{CO}_{2}$ and $\mathrm{H}_{2}$

Methanogenesis process generation from $\mathrm{CO}_{2}$ and $\mathrm{H}_{2}$ was introduced in the SWTM model. This process is mainly based on the finding that approximately $70 \%$ of methane is produced through HAc metabolism, while the remaining approximately $30 \%$ is produced from $\mathrm{H}_{2}$ and $\mathrm{CO}_{2}$ and from methyl nutrients (Taconi et al., 2008). Based on these percentages and the mass conservation law, the concentration of methyl substrates can be calculated as follows in Eq. (4):

$$
\mathrm{d} S / \mathrm{d} t=3 / 7 * \mathrm{~d} S_{\mathrm{CH}_{4}, \mathrm{HAC}} / \mathrm{d} t-\mathrm{d} S_{\mathrm{CH}_{4}, \mathrm{H}} / \mathrm{d} t .
$$

(6) Sulfate reduction

The sulfate reduction sub-model was introduced in the model. The process is based on the Monod and chemical equations (Barrera et al., 2015) and the scaling factor of the Monod equation and the metabolic rate of the substrates are listed in Table S1. The equation for this process is shown in Eq. (5).

$$
\mathrm{d} S_{i} / \mathrm{d} t=K_{\mathrm{H}_{2} S, i} * S_{i} /\left(S_{i}+K_{i}\right) * S_{\mathrm{SO}_{4}} /\left(S_{\mathrm{SO}_{4}}+k_{\mathrm{SO}_{4}}\right) * X_{S R B} .
$$

(7) Ammonification process

The ammonification sub-model was introduced in the model. As mentioned above, two processes are considered in this sub-model. A previous study shows that the degradation of urea to ammoniacal nitrogen is a firstorder reaction requiring the enzyme urease (Li et al., 2014). Hence, the sub-model is extended to one step with Eq. (6):

$$
\mathrm{d} S / \mathrm{d} t=K_{\text {amino }} * X .
$$

(8) $\mathrm{H}_{2} \mathrm{~S}$ air-water transformation

The $\mathrm{H}_{2} \mathrm{~S}$ air-water transformation process was introduced in the model. In this process, we adopt the two-film theory and assume that $\mathrm{H}_{2} \mathrm{~S}$ immediately reaches the equilibrium state between air and water. Based on this assumption, Henry's Law is used to calculate $\mathrm{H}_{2} \mathrm{~S}$ pressure.

As a weak acid, $\mathrm{H}_{2} \mathrm{~S}$ gas in the water phase can be dissociated in water, and the concentration of $\mathrm{H}_{2} \mathrm{~S}\left(\mathrm{~S}_{\mathrm{H} 2 \mathrm{~S}}\right)$ is calculated from Eq. (7):

$$
p H=p K_{a l}-\log \left(S_{\mathrm{H}_{2} S(\text { liquid })} /\left(1-S_{\mathrm{H}_{2} S}\right)\right) .
$$

In the Eq. (8), $K_{a l}$ is the ionization constant of $\mathrm{H}_{2} \mathrm{~S}$, and $p K_{a l}$ indicates $-\log K_{a 1}$. The value of $p K_{a l}$ is 7.0. In addition, $\mathrm{pH}$ can be simulated by the model created by 
Sharma et al. (2014). Based on Henry's law, the $\mathrm{H}_{2} \mathrm{~S}$ pressure is:

$$
P_{\mathrm{H}_{2} \mathrm{~S}}=H_{\mathrm{H}_{2} \mathrm{~S}} * S_{\mathrm{H}_{2} \mathrm{~S}} / 55.56 / 1000 .
$$

Because the atmospheric pressure in the sewer is $1 \mathrm{~atm}$., according to Dalton's law, the concentration of $\mathrm{H}_{2} \mathrm{~S}$ (gas) can be simulated as Eq. (9):

$$
S_{\mathrm{H}_{2} \mathrm{~S}}(\text { gas })=P_{\mathrm{H}_{2} \mathrm{~S}} * 0.0446 .
$$

Using these modifications, the matrix model shown in Table S1 was established, and the model processes and parameters are summarized in Table S2 and Table S3. In Table S1, the positive values represent generation, and the negative values represent consumption.

\subsection{The simulation steps}

The model is programmed in the Java platform. Due to the long length of sewer, not only the quality and quantity of the wastewater but also the thickness and composition of the biofilm show significant variations. Moreover, contaminants in sewers are primarily degraded by biofilm. Therefore, the calculation procedure is established by combining the characteristics of the sewer and the SWTM model:

As shown in Fig. 2, we introduce an L-coordinate, which is parallel to the sewage flow direction (Fig. 2). Based on this coordinate, a sewer fraction (length is $\mathrm{d} L$ ) is selected. When the length $(\mathrm{d} L)$ of the sewer fraction tends to zero, both the water quantity and the thickness of the biofilm in this part of sewer are constant. Essentially, organics transformation in a sewer fraction proceeds via three steps (Fig. 2) (Huisman and Gujer, 2002; Jiang et al., 2009). The first step is biofilm attachment or detachment. Second, pollutants diffuse to the biofilm. Third, these pollutants are metabolized in the biofilm. Based on these concepts, the multiple biofilm substrates model is used, which is shown in Eq. (10).

$$
r_{i}^{f}=a_{f}^{*} J_{i}=a_{f}^{*} \eta_{f, i} * L_{f}^{*} \Sigma\left(V_{j, i} * \rho_{j}^{f}\right) .
$$

In Eq. (10), $r_{i}^{f}$ is the consumption rate of the substrate. $a_{f}$ is the specific biofilm area $\left(\mathrm{m}^{2} / \mathrm{m}^{3}\right) ; J_{i}$ is the flux into the biofilm $\left(\mathrm{g} /\left(\mathrm{m}^{2} \cdot \mathrm{d}\right)\right) ; \eta_{f, i}$ is effectiveness factor; $L_{f}$ is the biofilm thickness (m); $v_{j, i}$ is the stoichiometric coefficient for compound $i$ and process $j$ (g-substrate $/ \mathrm{g}$-biomass); $\rho_{j}^{f}$ is the process rate for process $j$ within the biofilm $\left(\mathrm{g} /\left(\mathrm{m}^{3} \cdot \mathrm{d}\right)\right)$. The result of unit $\Sigma\left(V_{j, i}{ }^{*} \rho_{j}^{f}\right)$ in Eq. (10) is the uptake rate of substrates in all processes into the biomass.

Combining the assumptions of Huisman and Gujer (2002), Fick's second law of diffusion and Eq. (10), $\Sigma\left(V_{j, i} * \rho_{j}^{f}\right)$ is replaced by the corresponding components and parameters in the SWTM. After these modifications, the variation of water quality in the sewer fraction can be

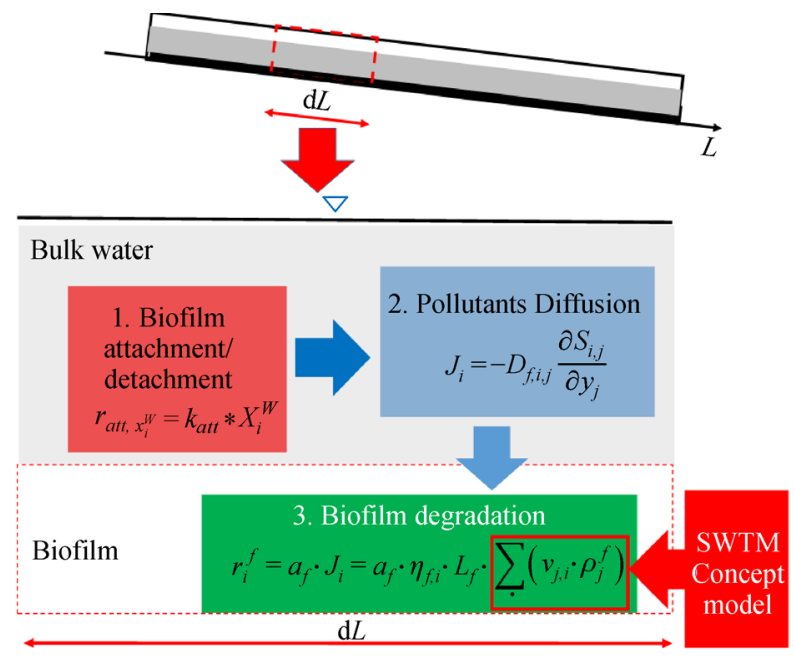

Fig. 2 Simulation flow chart.

given by Eq. (11) and Eq. (12).

$$
\begin{gathered}
\mathrm{d} S / \mathrm{d} t=r_{i}^{f}, \\
S_{\text {out }}=S_{\text {in }}+\mathrm{d} S .
\end{gathered}
$$

In Eq. (11), $r_{i}^{f}$ is the consumption rate of the substrate. $\mathrm{d} S$ is the concentration variation of substrate. In Eq. (12), $S_{\text {out }}$ is the effluent concentration of the substrate. $S_{\text {in }}$ is the influent concentration of the substrate. Since the consumption rate of the substrates $\left(r_{i}^{f}\right)$ in sewer is a continuous function of variable $L$, the variations in the concentrations of various pollutants or microorganisms can be calculated by integrating over the whole pipe. The initial condition at $L=0$ is reflected by the measurement data at $0 \mathrm{~m}$.

\subsection{Error analysis}

Errors analysis adopts the theory of probability (Bentler and Bonett, 1980) and uses the following equation:

$$
R^{2}=\Sigma e r^{2} / \Sigma\left(y_{i}-\bar{y}\right)
$$

In this equation, $e r=\left(y_{i}-y_{m, i}\right)$ represents the errors; $R^{2}$ is the goodness of fit statistics ranging from 0 to 1 . The higher the $R^{2}$ value, the better the model fits. The $R^{2}$ values in this study are listed in Table S4.

\section{Experimental methods}

\subsection{Pilot experimental system}

In this study, a laboratory-scale gravity sewer system was constructed to verify the accuracy of the developed model. It consisted of a $2-\mathrm{km}$ long PVC pipe with an inner diameter of $25 \mathrm{~mm}$ (Jin et al., 2015) and a slope of 0.005 . 
In this system, temperature, flow velocity and depth ratio were controlled at 25 centigrade, $0.6 \mathrm{~m} / \mathrm{s}$, and 0.6 , respectively. Seven sampling points were established at $0,200,400,600,800,1000$ and $1200 \mathrm{~m}$ from the inlet of the system, respectively. The length of pipe between two sampling points was removed to measure biofilm thickness, using the microelectrode method (Ramsing et al., 1993). The oxidation reduction potential (ORP) in the biofilm was also monitored, and the results show that the ORP ranged from -103 to $-346 \mathrm{mV}$, which indicated that the system operated in an anaerobic environment (Kreisberg et al., 1971).

In addition, the synthetic wastewater based on our previous study (Jin et al., 2015) was used to obtain the main parameters in the SWTM models. The synthetic wastewater consisted of: glucose, $\mathrm{NH}_{4} \mathrm{Cl}, \mathrm{Na}_{2} \mathrm{H}$ $\mathrm{PO}_{4} \cdot 12 \mathrm{H}_{2} \mathrm{O}, \mathrm{NaH}_{2} \mathrm{PO}_{4} \cdot 12 \mathrm{H}_{2} \mathrm{O}, \mathrm{KHCO}_{3}, \mathrm{NaHCO}_{3}, \mathrm{xFe}-$ $\mathrm{SO}_{4} \cdot 7 \mathrm{H}_{2} \mathrm{O}, \mathrm{CaCl}_{2}$, yeast, urea, peptone, soy peptone, tryptone and casein peptone provided at $200,60,25,25$, $50,130,50,2,2,3,30,30,20$ and $20 \mathrm{mg} / \mathrm{L}$, respectively. The COD, TN and TP levels of the synthetic wastewater were $370,45.5$ and $8.5 \mathrm{mg} / \mathrm{L}$, respectively.

\subsection{Analysis of microbes}

In this study, the total bacteria (TB), FB, HPA, methanogens (MA), SRB, and ammonifying bacteria (AB) were quantified using an Applied Biosystems 7500 qPCR instrument (Applied Biosystems, USA). Before the qPCR measurements were performed, the DNA was extracted from the biofilm with a Power Soil DNA Isolation Kit (MO Biomedical, USA) according to the manufacturer's protocol.

The PCR reaction mixture consisted of $8 \mu \mathrm{L}$ water, 12.5 $\mu \mathrm{L}$ TaKaRa SYBR ${ }^{\circledR}$ Premix Ex Taq ${ }^{\mathrm{TM}}, 1 \mu \mathrm{L}$ (each) primer, $0.5 \mu \mathrm{L} 50 \times$ ROX reference dye and $2 \mu \mathrm{L}$ template DNA. Specific primers for each bacteria type were employed in the reaction mixture. In this study, universal bacteria primer, iron hydrogenase (hydA), pctF/pctR, mlas/mcrArev, DSR2060F/DSR4R, nirSCd3aF/nirSR3cd and Bacillus F1/ Bacillus R1 were used to specifically amplify TB, FB, HPA, MA, SRB and AB (Rawsthorne et al., 2009; Steinberg and Regan, 2009; Pereyra et al., 2010; Li et al., 2013; Liu et al., 2015), respectively.

The RT-PCR was carried out as follows (Pereyra et al., 2010): initial denaturation at $95^{\circ} \mathrm{C}$ for $3 \mathrm{~min}, 40$ cycles at $95^{\circ} \mathrm{C}$ for $40 \mathrm{~s}$, various annealing temperatures $\left(56^{\circ} \mathrm{C}\right.$, $56^{\circ} \mathrm{C}, 55^{\circ} \mathrm{C}, 55^{\circ} \mathrm{C}, 55^{\circ} \mathrm{C}, 58^{\circ} \mathrm{C}$ and $55^{\circ} \mathrm{C}$ for $\mathrm{TB}, \mathrm{FB}, \mathrm{HPA}$, $\mathrm{MA}, \mathrm{SRB}, \mathrm{DNB}$ and $\mathrm{AB}$, respectively) for $30 \mathrm{~s}$ and elongation at $72^{\circ} \mathrm{C}$ for $30 \mathrm{~s}$, and a final extension at $72^{\circ} \mathrm{C}$ for $5 \mathrm{~min}$.

\subsection{Pollutants analysis}

Water samples were filtered through a $0.45 \mu \mathrm{m}$ membrane before the measurements, except for the analysis of protein lipids and carbohydrates. The methods used for the measurement of VFAs, ethanol, lactic acid and other pollutants are presented in supplemental information (Supplementary material S2).

\section{Model simulation and calibration}

\subsection{Microorganism Simulation}

The variation in TB levels was simulated as illustrated in Fig. 3, where TB increased along the sewer. At the beginning of the sewer, substrates were relatively abundant, resulting in the growth and metabolism of anaerobic microorganisms (Uggetti et al., 2014). At this stage, macromolecular substances were degraded by microorganisms into smaller molecules (Jin et al., 2015). Hence, the amount of macromolecules decreased, and smaller molecules substances increased. Since both macromolecules and small molecules can be absorbed and utilized by bacterial (Jin et al., 2015), the number of TB increased.

The dynamics of four dominant bacterial communities, specifically HPA, MA, SRB and AB were simulated. As shown in Fig. 3, owing to the low concentrations of VFAs and sugar, the number of HPA was relatively low at the beginning of the sewer. However, as VFAs accumulated along the sewer, HPA reproduced rapidly after the beginning segment of the sewer. After $800 \mathrm{~m}$ into the sewer, an equilibrium was reached between the consumption and generation of VFAs, and the number of HPA stabilized. These changes in the HPA community resulted in an increase of HAc levels, which favors the growth of MA (Liu and Boone, 1991). In addition, the concentration of $\mathrm{SRB}$ and $\mathrm{AB}$ remained relatively stable along the sewer, which probably reflect the levels of sulfate and amino acids which was the available substrates of $\mathrm{SRB}$ and $\mathrm{AB}$, respectively.

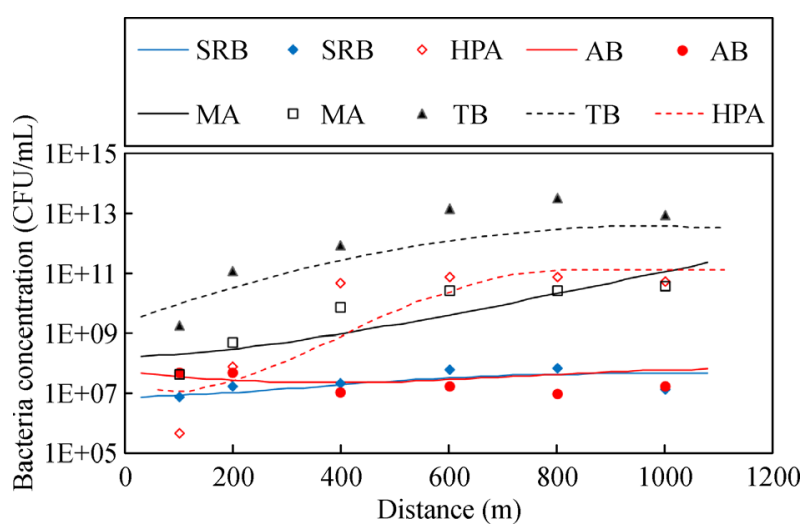

Fig. 3 Simulation results for the main bacteria species along the sewer (lines represent the simulation result and points represent the measurement data). 


\subsection{Simulation of pollutant transformation in the sewer}

Based on the microbial variations, the processes of fermentation, generation of gaseous metabolites, ammonification and sulfate reduction in the sewer were investigated.

The simulation results of the fermentation process (Fig. 4(a)) show that VFAs mainly consisted of HAc, $\mathrm{HBu}$ and HPro, in which HAc was the major component with the highest concentration. As the distance from the inlet increased, the concentration of $\mathrm{HAc}, \mathrm{HBu}$ and HPro all increased, resulting in the rising VFA concentration. In addition, the concentration of lactic acid also increased along the beginning of sewer up to $200 \mathrm{~m}$ and then gradually decreased beyond this point. The changes in ethanol concentration followed a similar pattern as that of lactic acid, reaching its maximum at a distance of $100 \mathrm{~m}$. During the hydrolysis fermentation process, macromolecular organics are constantly decomposed into small organic molecules such as VFA, lactic acid and ethanol (Vavilin, 2002). Furthermore, lactic acid and ethanol tend to be transformed into HAc. Therefore, the concentration of VFAs gradually increases in sewers. Among the VFAs,
HAc reaches the highest concentrations, which is mainly attributed to the transformation of $\mathrm{HBu}$ and HPro into HAc.

The changes in the levels of other fermentation products $\left(\mathrm{H}_{2}, \mathrm{CH}_{4}\right.$ and $\left.\mathrm{CO}_{2}\right)$ in the sewer were also investigated. As shown in Fig. 4(b), the concentration of $\mathrm{H}_{2}$ increased along the sewer for the first $300 \mathrm{~m}$ and then gradually decreased, while the concentrations of $\mathrm{CH}_{4}$ and $\mathrm{CO}_{2}$ increased continuously along the sewer. HAc can be decomposed during methanogenic and sulfate-reduction processes. As shown in Fig. 3, regarding MA and SRB, only MA increased in a stable manner along the sewer. MA can transform HAc into methane, and approximately $70 \%$ of methane is generated through this process (Sun et al., 2018). The steady increase of MA led to increases in both the concentration of methane and the consumption of HAc along the sewer. After $300 \mathrm{~m}$ into the sewer, due to the high consumption of $\mathrm{HAc}, \mathrm{H}_{2}$ was used by the homoacetogenic bacteria to produce more HAc, which was further metabolized by MA for methane production. These processes therefore eventually deplete the levels of $\mathrm{H}_{2}$ in the sewer. Moreover, because both reactions leading to the formation of $\mathrm{HAc}$ and methane from $\mathrm{HAc}$ produce $\mathrm{CO}_{2}$,

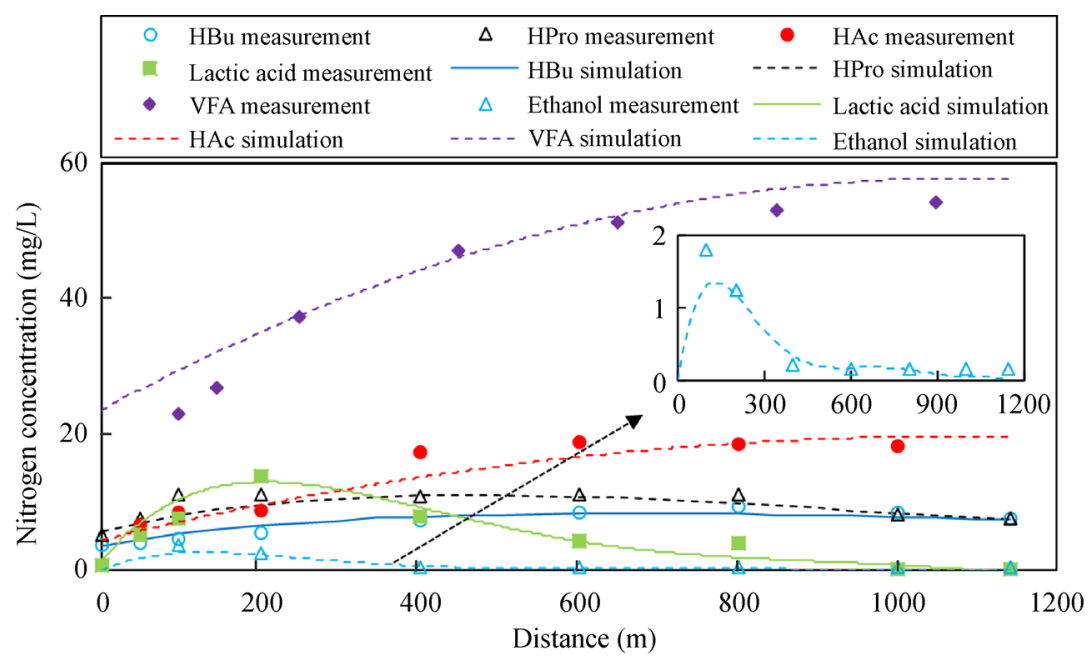

(a)

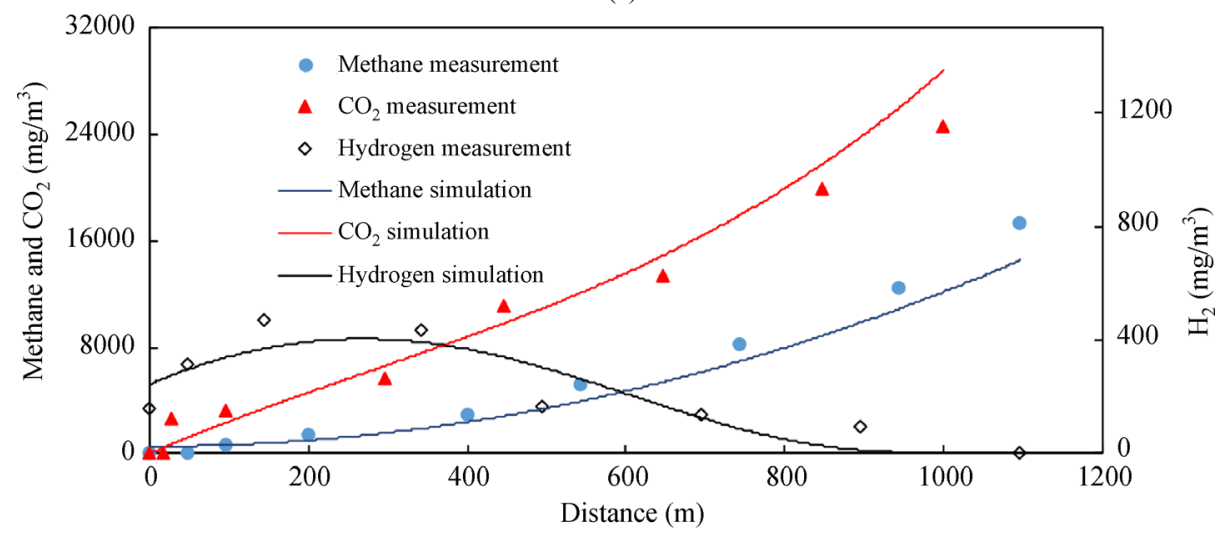

(b)

Fig. 4 The simulation results for: (a) organic matter transformation; (b) generation of gases. 
the concentration of $\mathrm{CO}_{2}$ tends to increase constantly and always remains higher than that of methane (Vavilin, 2002). Therefore, HAc is an important fermentation product that promotes microbial metabolism and other organic matter (propionate, lactic acid, etc.) tends to be converted into HAc via biochemical metabolism.

Nitrogen transformation in the sewer was also investigated in this study. As shown in Fig. 5(a), the concentration of urea decreased quickly along the sewer, indicating that the relevant enzyme reactions occur in the sewer ( $\mathrm{Li}$ et al., 2014). Owing to the high concentration of urea its degradation rate was relatively high, resulting in decreasing concentrations of urea as the distance from the sewer inlet increased. Similarly, the degradation process of proteins is also an enzymatic reaction (Onifade et al., 1998). The relatively low hydrolysis constant (Onifade et al., 1998) and high concentration of the substrate accelerates the decomposition of proteins. Therefore, protein concentration decreased along the length of the sewer. Because proteins can be converted into amino acids, the concentration of amino acids increased resulting in an increase in the consumption rate of amino acids. After 600 $\mathrm{m}$, the amino acid consumption rate surpassed its generation rate, thus, the concentration of amino acids along the sewer first increased and then decreased.

Ammonia is a final product of the anaerobic state, and two processes can produce it: hydrolysis of urea and degradation of organic nitrogen compounds (Rajagopal et al., 2013). As shown in Fig. 5a, ammonia was continually generated along the sewer due to the constant decomposition of urea and organic nitrogen compounds. Moreover, it should be noted that ammonia was mainly generated from urea at the beginning of the sewer due to rapid consumption of urea. After $600 \mathrm{~m}$, owing to the low degradation rate of urea, the increase of ammonia mainly results from the decomposition of organic nitrogen

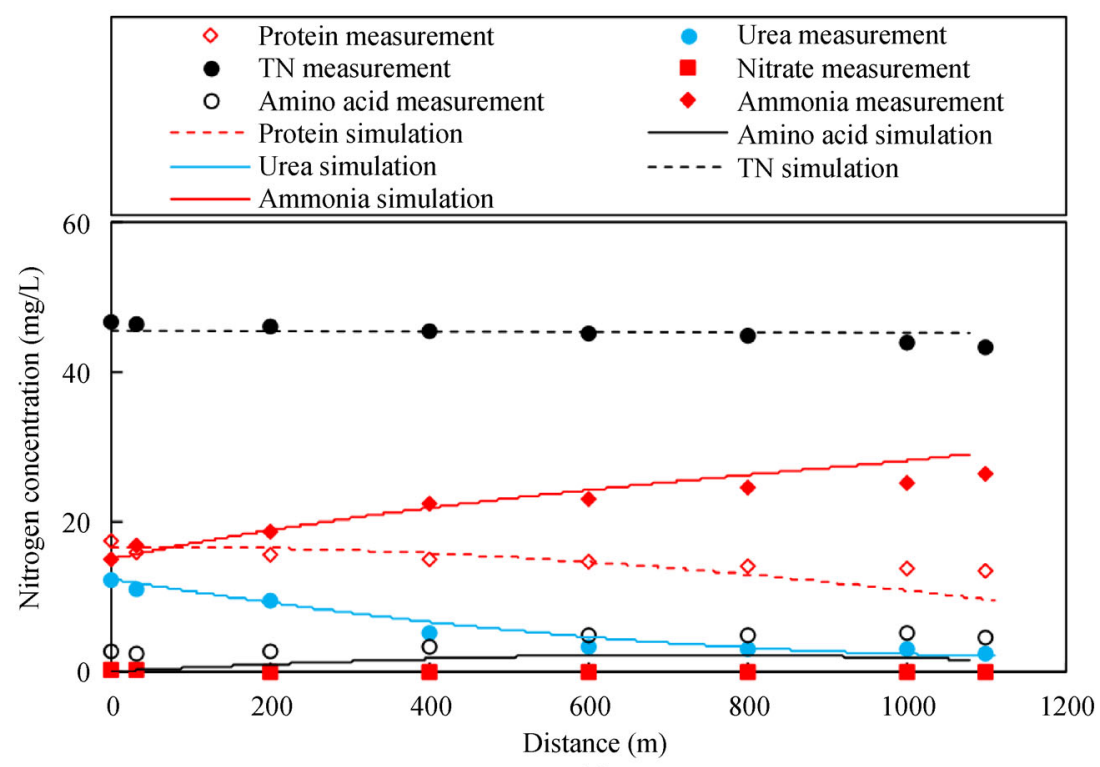

(a)

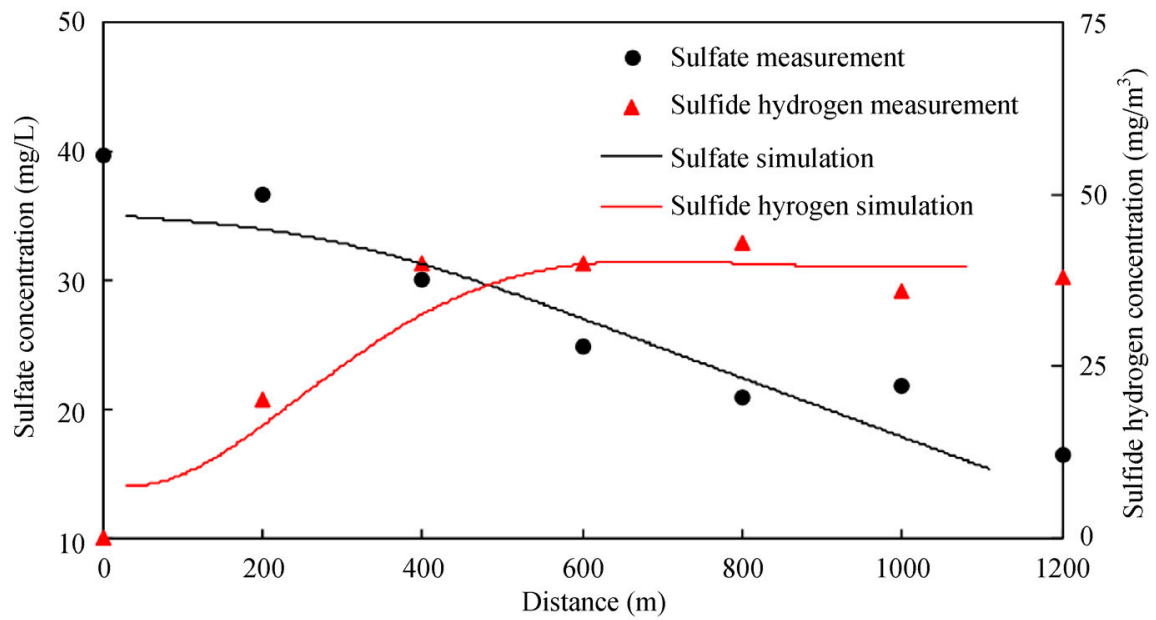

(b)

Fig. 5 The validation results for: (a) ammonification process, and (b) sulfate reduction process. 
substances. Since ammonia emissions were almost negligible in the sewer, the TN remained constant based on the conservation of mass.

The sulfate reduction process was also simulated. As shown in Fig. 5(b), the concentration of sulfate along the sewer decreased continuously. Meanwhile, the concentration of $\mathrm{H}_{2} \mathrm{~S}$ first steadily increased and then became relatively stable after $600 \mathrm{~m}$ in the sewer. SRB are able to transform $\mathrm{SO}_{4}{ }^{2-}$ into $\mathrm{H}_{2} \mathrm{~S}$ by metabolizing certain VFAs and other carbon sources (Jin et al., 2015). At the beginning of the sewer, an increasing number of SRB transformed $\mathrm{SO}_{4}{ }^{2-}$ into $\mathrm{H}_{2} \mathrm{~S}$. After $600 \mathrm{~m}$, the SRB levels stabilized, resulting in a stable the $\mathrm{H}_{2} \mathrm{~S}$ concentration as well.

4.3 Functional analysis of acetic acid in biochemical reaction process in the sewer

HAc is the most important product of the fermentation process by affecting many other processes in the sewer. For this reason, we investigated how HAc was involved in different metabolic processes. Because $\mathrm{AB}$ use amino acids as their sole carbon source (Sepers, 1981), this analysis is limited to simulating the contribution of different carbon sources to methane production and sulfate reduction.
As shown in Fig. 6(a), in a finding consistent with what occurs in a semi-continuous reactor system (Taconi et al., 2008), methane was also generated mainly from HAc, followed by methane from $\mathrm{H}_{2}$ and $\mathrm{CO}_{2}$; methyl nutrients generate the least methane. This can be attributed to the fact that the accumulation of HAc prompts methanogens to preferentially utilize HAc rather than other carbon sources. This study found that the methane produced by $\mathrm{CO}_{2}$ and $\mathrm{H}_{2}$ metabolism accounted for $25.3 \pm 1.4 \%$ of the total methane and methane produced by methyl substrates accounted for less than $3.7 \pm 0.5 \%$. The rest of the methane originated from HAc.

In the simulation of the sulfate reduction process, HAc, HPro and HBu were used as carbon sources. These carbon sources had the same initial concentrations and the initial sulfate concentration also remained constant. As shown in Fig. 6(b), the slope of the consumption curve of HPro is greater than that of HAc and the metabolic yield of HPro is higher than that of HAc within $80 \mathrm{~min}$. The results suggest that in the sulfate reduction process, the HPro reaction rate is faster than HAc, thus HAc is not the main metabolic substance. Fedorovich et al. (2003) demonstrated that in the sulfate reduction process, both the half-saturation constant and maximum uptake rate for HAc are much lower than those for HPro. In this study, the yield

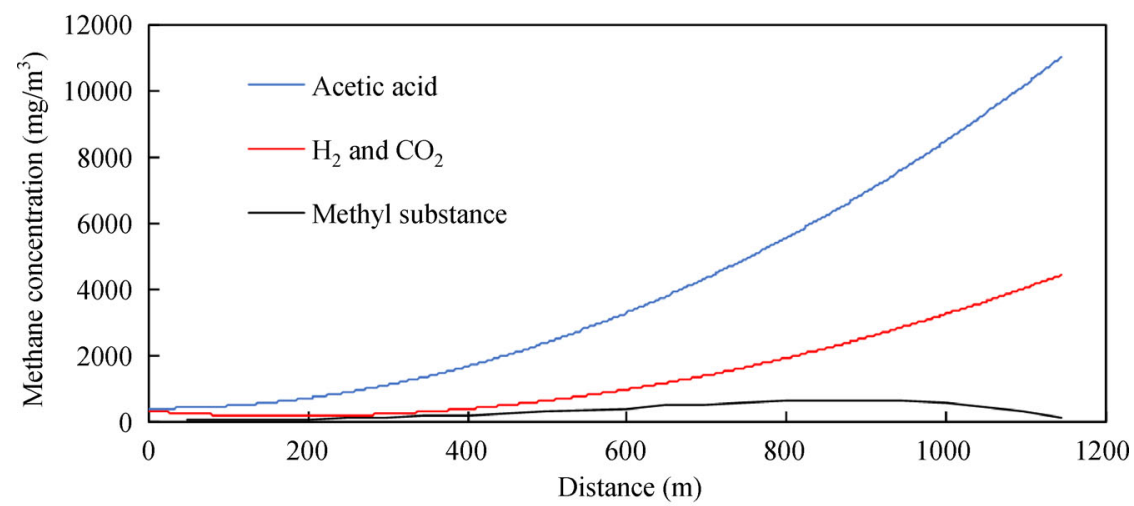

(a)

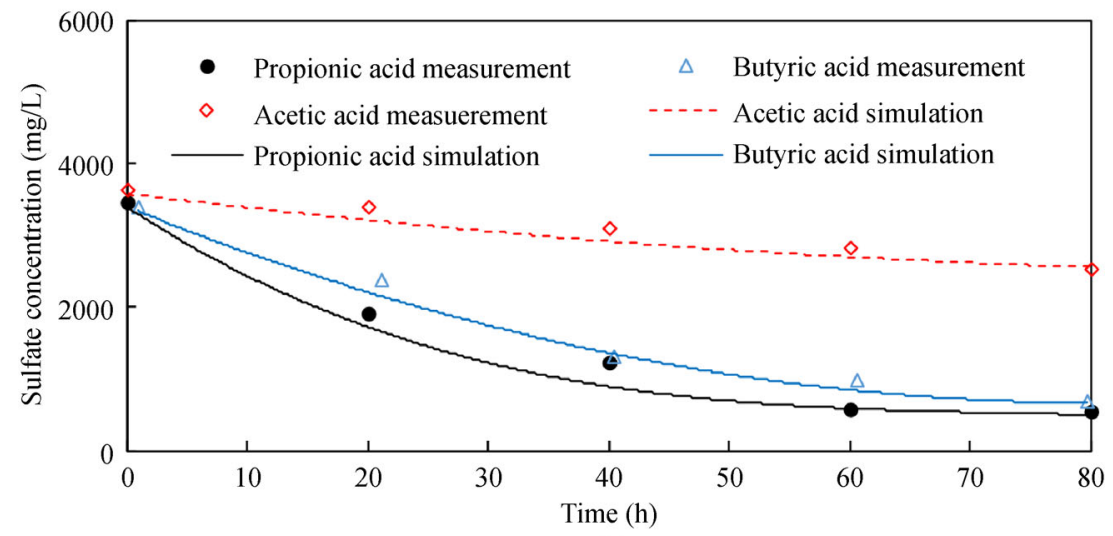

(b)

Fig. 6 Functional analysis of the HAc biochemical reaction process in sewer: (a) methanogenesis; (b) sulfate reduction. The measurement data are derived from Song and Zhang (2011). 
Table 1 Model validation with fermentation data from Guisasola et al. (2009)

\begin{tabular}{lccccccc}
\hline Reaction times $(\mathrm{min})$ & 0 & 10 & 20 & 30 & 40 & 50 & 60 \\
\hline Acetic acid measurement (mg/L) & 34.60 & 38.20 & 38.70 & 40.00 & 42.30 & 45.00 & 45.90 \\
Acetic acid Simulation $(\mathrm{mg} / \mathrm{L})$ & 34.60 & 37.15 & 39.66 & 42.60 & 45.42 & 47.56 & 48.45 \\
Butyric acid measurement $(\mathrm{mg} / \mathrm{L})$ & 11.03 & 9.00 & 7.80 & 7.65 & 7.54 & 6.03 & 8.34 \\
Butyric acid simulation $(\mathrm{mg} / \mathrm{L})$ & 11.03 & 9.45 & 8.14 & 7.10 & 6.32 & 5.79 & 5.53 \\
Methane measurement $\left(\mathrm{mg} / \mathrm{m}^{3}\right)$ & 0.34 & 1.20 & 3.41 & 5.12 & 5.74 & 7.03 & 8.61 \\
Methane simulation $\left(\mathrm{mg} / \mathrm{m}^{3}\right)$ & 0.34 & 1.58 & 2.90 & 4.17 & 5.40 & 6.57 & 7.69 \\
Sulfate measurement $(\mathrm{mg} / \mathrm{L})$ & 83.23 & 79.01 & 73.41 & 69.98 & 65.70 & 62.03 & 61.83 \\
Sulfate simulation $(\mathrm{mg} / \mathrm{L})$ & 83.23 & 75.88 & 70.41 & 65.86 & 63.21 & 61.31 & 60.20 \\
\hline
\end{tabular}

coefficients (kg COD-substrate/kg COD-carbon source) for HAc, HPro and $\mathrm{HBu}$ were $0.03,0.2$ and 0.2 , respectively, and the half-saturation coefficients $(\mathrm{kg}$ $\mathrm{COD} / \mathrm{m}^{3}$ ) for HAc, HPro and $\mathrm{HBu}$ were $0.8,20$ and 16 , respectively. These parameters indicate that HAc is not the preferred substance for SRB growth. And the Monod equation calculation supports this result, i.e., HAc yields a much lower metabolic rate than HPro. However, due to the low concentration of sulfate and SRB in the sewer, the effect of acetic acid concentration on sulfate reduction can be ignored.

\subsection{Model Verification}

The above results indicate that the SWTM is well supported by experimental data. Fermentation data from Guisasola et al. (2009) were used to further verify this model. We used two methods for verification. The first method is a goodness of fit test. As shown in Table 1, the model simulation fits well with data from the fermentation processes, with $R^{2}$ values of the fermentation process reached $0.92,0.93,0.91$ and 0.89 . The other method was the bias factor $\left(B_{f}\right)$ test (Ross, 1996). In the fermentation process, $B_{f}$ values ranged from 0.91 to 1.05 . These values are within the range of reasonable $B_{f}$ values for bio-kinetic models (between 0.7 and 1.19) (Ross,1996). Moreover, the closer the $B_{f}$ value is to 1 , the better the model fits. Therefore, we conclude that the current model is highly precise.

\section{Conclusions}

A SWTM model was developed and verified. The main conclusions are as follows:

- The model first describes the comprehensive biochemical reactions concerning sulfate reduction, ammonification, hydrolysis, acidogenesis and methanogenesis processes in a gravity sewer system.

- The model incorporates known pollutant transformation characteristics for example, organic matter is first degraded into intermediate products and then metabolized into acetic acid. This process was successfully validated by comparing simulation results with the previous findings from relevant literature.

- The simulation results clearly reveal that each biochemical reaction has a corresponding and specific carbon source e.g., sulfate-reducing bacteria prefer to use propionic acid rather than acetic acid, and the substrates preferred by methanogens during methane production follows the order: acetic acid $>\mathrm{H}_{2}$ and $\mathrm{CO}_{2}>$ methyl nutrients. And among these carbon sources, acetic acid is the most important substrate by greatly affecting many major processes in the sewer, such as fermentation and methanogenesis.

- This model considers the different biochemical reaction processes that occur in sewers and provides a comprehensive approach for predicting the quality of wastewater.

\begin{tabular}{|c|c|c|}
\hline \multicolumn{3}{|l|}{ Nomenclature } \\
\hline Parameters & Meanings & Unit \\
\hline$\overline{a_{f}}$ & The specific biofilm area & $\mathrm{m}^{2} / \mathrm{m}^{3}$ \\
\hline$H_{\mathrm{H}_{2} \mathrm{~S}}$ & Henry's constant for $\mathrm{H}_{2} \mathrm{~S}$ & $\mathrm{~Pa} \cdot \mathrm{L} / \mathrm{mg}$ \\
\hline$f_{\text {substrate }}$ & Yield of substrate on sugar. & kg COD-substrate/kg COD-sugar \\
\hline$f_{\text {products,substrate }}$ & Yield of products on substrates & $\mathrm{kg}$ COD-products $\cdot \mathrm{kg} / \mathrm{COD}$-substrates \\
\hline$J_{i}$ & The flux into the biofilm & $\mathrm{g} /\left(\mathrm{m}^{2} \cdot \mathrm{d}\right)$ \\
\hline$k_{\mathrm{H}_{2} \mathrm{~S}, i}$ & Specific maximum uptake rate for carbon $i$ in sulfate reduction & $\mathrm{kg}$ COD-substrate/(kg COD-carbon source $\cdot \mathrm{d})$ \\
\hline$k_{m, \text { substrate }}$ & Specific maximum uptake rate of substrate & $\mathrm{kg}$ COD-substrate/(kg COD-biomass $\cdot \mathrm{d})$ \\
\hline$k_{m, \text { homo }}$ & Specific maximum uptake rate in homoacetogenesis & $\mathrm{kg} \mathrm{COD}$-substrate/(kg COD-biomass $\cdot \mathrm{d})$ \\
\hline
\end{tabular}




\begin{tabular}{|c|c|c|}
\hline Parameters & Meanings & Unit \\
\hline$k_{\text {substrate }}$ & Half-saturation coefficient of substrate & $\mathrm{kmol} / \mathrm{m}^{3}$ \\
\hline$k_{s, h o m o}$ & Half saturation coefficient in homoacetogenisis & $\mathrm{kg} \mathrm{COD} / \mathrm{m}^{3}$ \\
\hline$k_{\mathrm{SO}_{4}, i}$ & Half saturation coefficient of carbon $i$ in sulfate reduction & $\mathrm{kmol} / \mathrm{m}^{3}$ \\
\hline$L_{f}$ & Biofilm thickness & $\mathrm{m}$ \\
\hline$r_{i}^{f}$ & Concentration generation (consumption) rate for substrate & $\mathrm{mg} /(\mathrm{L} \cdot \min )$ \\
\hline$P_{\mathrm{H}_{2} \mathrm{~S}}$ & The hydrogen sulfide pressure & $\mathrm{Pa}$ \\
\hline$S$ & Concentration & $\mathrm{mg} / \mathrm{L}$ \\
\hline$S_{\mathrm{CH}_{4} \text {,substrate }}$ & Methane generated from substrate & $\mathrm{mg} / \mathrm{m}^{3}$ \\
\hline$S_{\text {substrate }}$ & Concentration of substrate & $\mathrm{kg} \mathrm{COD} / \mathrm{m}^{3}$ \\
\hline$S_{i}$ & Carbon content of component $i$ & $\mathrm{~kg} \mathrm{COD} / \mathrm{m}^{3}$ \\
\hline$S_{\text {in }}$ & The influent concentration of the substrate & $\mathrm{mg} / \mathrm{L}$ \\
\hline$S_{\text {out }}$ & The effluent concentration of the substrate & $\mathrm{mg} / \mathrm{L}$ \\
\hline$X_{\text {alcohol }}$ & Ethanol consuming microorganism & copies $/ \mathrm{mL}$ \\
\hline$X_{\text {homo }}$ & Homoacetogenic bacteria & copies $/ \mathrm{mL}$ \\
\hline$X_{S R B}$ & SRB & copies $/ \mathrm{mL}$ \\
\hline$Y_{\text {substrate }}$ & Biomass yield on substrate & kg COD-biomass/kg COD-substrate \\
\hline$Y_{\text {homo }}$ & Biomass yield on homoacetogenesis process & kg COD-biomass $/ \mathrm{kg}$ COD-substrate \\
\hline$\eta_{f, i}$ & The effectiveness factor & \\
\hline
\end{tabular}

Acknowledgements This work was financially supported by the National Key Project of Water Pollution Control and Management (Grant No. 2012ZX07313-001), the New Century Excellent Talents Award Program from Education Ministry of China (Grant No. NCET-12-1043), and the Program for Innovative Research Team in Shaanxi Province (Grant No. 2013KCT-13).

Electronic Supplementary Material Supplementary material is available in the online version of this article at https://doi.org/10.1007/s11783-0191144-1 and is accessible for authorized users.

\section{References}

Abdul-Talib S, Hvitved-Jacobsen T, Vollertsen J, Ujang Z (2002). Half saturation constants for nitrate and nitrite by in-sewer anoxic transformations of wastewater organic matter. Water Science and Technology, 46(9): 185-192

Barrera E L, Spanjers H, Solon K, Amerlinck Y, Nopens I, Dewulf J (2015). Modeling the anaerobic digestion of cane-molasses vinasse: Extension of the Anaerobic Digestion Model No. 1 (ADM1) with sulfate reduction for a very high strength and sulfate rich wastewater. Water Research, 71: 42-54

Bentler P M, BonettD G (1980). Significance tests and goodness of fit in the analysis of covariance structure. Psychological Bulletin, 88(3): 588-606

Cravo-Laureau C, Labat C, Joulian C, Matheron R, Hirschler-Réa A (2007). Desulfatiferula olefinivorans gen. nov., sp. nov., a long-chain n-alkene-degrading, sulfate-reducing bacterium. International Journal of Systematic and Evolutionary Microbiology, 57(11): 2699-
2702

Fedorovich V, Lens P, Kalyuzhnyi S (2003). Extension of Anaerobic Digestion Model No. 1 with processes of sulfate reduction. Applied Biochemistry and Biotechnology, 109(1-3): 33-46

Fu G, Makropoulos C, Butler D (2010). Simulation of urban wastewater systems using artificial neural networks: Embedding urban areas in integrated catchment modelling. Journal of Hydroinformatics, 12(2): 140-149

Garsdal H, Mark O, Dorge J, Jepsen S (1995). Mousetrap: Modelling of water quality processes and the interaction of sediments and pollutants in sewers. Water Science and Technology, 31(7): 33-41

Guisasola A, Sharma K R, Keller J, Yuan Z (2009). Development of a model for assessing methane formation in rising main sewers. Water Research, 43(11): 2874-2884

Higashioka Y, Kojima H, Nakagawa T, Sato S, Fukui M (2009). A novel n-alkane-degrading bacterium as a minor member of p-xylenedegrading sulfate-reducing consortium. Biodegradation, 20(3): 383390

Huisman J L, Gujer W (2002). Modelling wastewater transformation in sewers based on ASM3. Water Science and Technology, 45(6): 5160

Hvitved-Jacobsen T, Vollertsen J, Nielsen P H (1998). A process and model concept for microbial wastewater transformations in gravity sewers. Water Science and Technology, 37(1): 233-241

Jiang F, Leung D H, Li S, Chen G H, Okabe S, van Loosdrecht M C (2009). A biofilm model for prediction of pollutant transformation in sewers. Water Research, 43(13): 3187-3198

Jiang F, Leung H W, Li S Y, Lin G S, Chen G H (2007). A new method for determination of parameters in sewer pollutant transformation 
process model. Environmental Technology, 28(11): 1217-1225

Jie W, Peng Y, Ren N, Li B (2014). Volatile fatty acids (VFAs) accumulation and microbial community structure of excess sludge (ES) at different pHs. Bioresource Technology, 152: 124-129

Jin P, Shi X, Sun G, Yang L, Cai Y, Wang X C (2018). Co-variation between distribution of microbial communities and biological metabolization of organics in urban sewer systems. Environmental Science \& Technology, 52(3): 1270-1279

Jin P, Wang B, Jiao D, Sun G, Wang B, Wang X C (2015). Characterization of microflora and transformation of organic matters in urban sewer system. Water Research, 84: 112-119

Jing Z, Hu Y, Niu Q, Liu Y, Li Y Y, Wang X C (2013). UASB performance and electron competition between methane-producing archaea and sulfate-reducing bacteria in treating sulfate-rich wastewater containing ethanol and acetate. Bioresource Technology, 137: 349-357

Kreisberg R A, Siegal A M, Owen W C (1971). Glucose-lactate interrelationships: Effect of ethanol. Journal of clinical investigation, 50(1): 175-185

Li H, Song Y, Li Q, He J, Song Y (2014). Effective microbial calcite precipitation by a new mutant and precipitating regulation of extracellular urease. Bioresource Technology, 167: 269-275

Li Y F, Wei S, Yu Z (2013). Feedstocks affect the diversity and distribution of propionate CoA-transferase genes $(p c t)$ in anaerobic digesters. Microbial Ecology, 66(2): 351-362

Liu H, Yu T, Liu Y (2015). Sulfate reducing bacteria and their activities in oil sands process-affected water biofilm. The Science of the total environment, 536: 116-122

Liu Y, Boone D R (1991). Effects of salinity on methanogenic decomposition. Bioresource Technology, 35(3): 271-273

Mackey H R, Rey Morito G, Hao T, Chen G H (2016). Pursuit of urine nitrifying granular sludge for decentralised nitrite production and sewer gas control. Chemical Engineering Journal, 289: 17-27

Nie Y Q, Liu H, Du G C, Chen J (2007). Enhancement of acetate production by a novel coupled syntrophic acetogenesis with homoacetogenesis process. Process Biochemistry, 42(4): 599-605

Onifade A A, Al-Sane N A, Al-Musallam A A, Al-Zarban S (1998). A review: Potentials for biotechnological applications of keratindegrading microorganisms and their enzymes for nutritional improvement of feathers and other keratins as livestock feed resources. Bioresource Technology, 66(1): 1-11

Pandey S K, Kim K H, Kwon E E, Kim Y H (2016). Hazardous and odorous pollutants released from sewer manholes and stormwater catch basins in urban areas. Environmental Research, 146: 235-244

Pereyra L P, Hiibel S R, Prieto Riquelme M V, Reardon K F, Pruden A (2010). Detection and quantification of functional genes of cellulosedegrading, fermentative, and sulfate-reducing bacteria and methanogenic archaea. Applied and Environmental Microbiology, 76(7): 2192-2202

Rahman A, Kumashiro M, Ishihara T (2011). Direct synthesis of formic acid by partial oxidation of methane on H-ZSM-5 solid acid catalyst. Catalysis Communications, 12(13): 1198-1200

Rajagopal R, Massé D I, Singh G (2013). A critical review on inhibition of anaerobic digestion process by excess ammonia. Bioresource Technology, 143: 632-641
Ramsing N B, Kühl M, Jørgensen B B (1993). Distribution of sulfatereducing bacteria, $\mathrm{O} 2$, and $\mathrm{H}_{2} \mathrm{~S}$ in photosynthetic biofilms determined by oligonucleotide probes and microelectrodes. Applied and Environmental Microbiology, 59(11): 3840-3849

Rawsthorne H, Dock C N, Jaykus L A (2009). PCR-based method using propidium monoazide to distinguish viable from nonviable Bacillus subtilis spores. Applied and Environmental Microbiology, 75(9): 2936-2939

Ren N, Wang B, Huang J C (1997). Ethanol-type fermentation from carbohydrate in high rate acidogenic reactor. Biotechnology and Bioengineering, 54(5): 428-433

Ren N, Wang Q, Wang Q, Huang H, Wang X (2017). Upgrading to urban water system 3.0 through sponge city construction. Frontiers of Environmental Science \& Engineering, 11(4): 9

Ross T (1996). Indices for performance evaluation of predictive models in food microbiology. The Journal of applied bacteriology, 81(5): 501-508

Rudelle E, Vollertsen J, Hvitved-Jacobsen T, Nielsen A H (2011). Anaerobic transformations of organic matter in collection systems. Water Environment Research A: Research Publication of the Water Environment Federation, 83(6): 532-540

Schmitt F, Seyfried C F (1992). Sulfate reduction in sewer sediments. Water Science and Technology, 25(8): 83-90

Sepers A B J (1981). Diversity of ammonifying bacteria. Hydrobiologia, 83(2): 343-350

Sharma K, Derlon N, Hu S, Yuan Z (2014). Modeling the pH effect on sulfidogenesis in anaerobic sewer biofilm. Water Research, 49: 175185

Sharma K, Ganigue R, Yuan Z (2013). pH dynamics in sewers and its modeling. Water Research, 47(16): 6086-6096

Song X, Zhang Z (2011). Notice of Retraction Sulfate Reducing Rate of SRB with Acetic, Propionic, n-Butyric Acids as Carbon Sources. In: The 5th International Conference on Bioinformatics and Biomedical Engineering, Wuhan. New York: Curran Associates, 1-4

Steinberg L M, Regan J M (2009). mcrA-targeted real-time quantitative PCR method to examine methanogen communities. Applied and Environmental Microbiology, 75(13): 4435-4442

Sun Y, Zhao J, Chen L, Liu Y, Zuo J (2018). Methanogenic community structure in simultaneous methanogenesis and denitrification granular sludge. Frontiers of Environmental Science \& Engineering, 12(4): 10

Taconi K A, Zappi M E, Todd French W, Brown L R (2008). Methanogenesis under acidic $\mathrm{pH}$ conditions in a semi-continuous reactor system. Bioresource Technology, 99(17): 8075-8081

Uggetti E, Sialve B, Latrille E, Steyer J P (2014). Anaerobic digestate as substrate for microalgae culture: the role of ammonium concentration on the microalgae productivity. Bioresource Technology, 152(152): 437-443

Vavilin V A (2002).The IWA Anaerobic Digestion Model No. 1. London: IWA Publishing

Widdel F, Pfennig N (1977). A new anaerobic, sporing, acetateoxidizing, sulfate-reducing bacterium, Desulfotomaculum (emend.) acetoxidans. Archives of Microbiology, 112(1): 119-122

Yuan D, Rao K, Relue P, Varanasi S (2011). Fermentation of biomass sugars to ethanol using native industrial yeast strains. Bioresource Technology, 102(3): 3246-3253 